This journal is the official publication of Bangladesh Society of Physiologists (BSP)

Web URL: www.banglajol.info/index.php/JBSP

Abstracted /indexed in Index Copernicus, Director of Open Access Journal, Index Medicus for South East Asia Region, Google Scholar, 12OR, infobse index, Open J gate, Cite factor, Scientific indexing services

pISSN-1983-1213; e-ISSN-2219-7508

\title{
Article
}

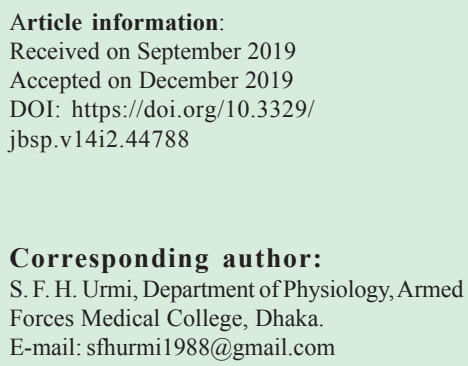

J Bangladesh Soc Physiol 2019;14(2): 77-81

This article is open access licensed under CC BY NC SA which allows readers copy, distribute, display, and perform the work and make derivative works based on it only for noncommercial purposes.

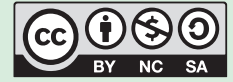

\section{Evaluation of parathyroid function in adult male patients with transfusion dependent thalassemia}

\author{
S. F. H. Urmi ${ }^{1}$, Shelina Begum ${ }^{2}$, Fatema Tuz Munira ${ }^{1}$ \\ 1. Department of Physiology, Armed Forces Medical College, Dhaka \\ 2. Department of Physiology, Bangabandhu Sheikh Mujib Medical \\ University, Dhaka
}

\section{Abstract}

Background: In transfusion dependent thalassemic (TDT) patients regular blood transfusion leads to iron overload. This increased iron is deposited in the tissue of various system and causes organ damage. Endocrine dysfunction is very common due to iron deposition into the endocrine glands including parathyroid dysfunction.Objective: To measure plasma intact parathyroid hormone(iPTH), serum total calcium and inorganic phosphate levels in adult male patients with TDT.Methods: This cross sectional study was conducted in the Department of Physiology, Bangabandhu Sheikh Mujib Medical University, Dhaka from March 2018 to February 2019. Total 35 TDT male patients aged 18 to 40 year and 35 age matched apparently healthy male subjects were enrolled for this study as control. The TDT patients were selected from the outpatient department of Hematology and Transfusion Medicine. For assessment of parathyroid function serum albumin, plasma iPTH, serum total calcium and inorganic phosphate levels were estimated by colorimetric method using automated analyzer. For statistical analysis, independent sample t test was done.Results: In this study, plasma iPTH and serum corrected calcium levels were significantly $(\mathrm{p}<0.001)$ lower in patients with TDT than those of healthy control. Again, Serum inorganic phosphate and ALP levels were significantly $(\mathrm{p}<0.001)$ higher in patients with TDT than those of healthy control. Moreover, $2.86 \%$ of TDT patients had low iPTH. Conclusion: From this study, it can be concluded that reduced parathyroid function was associated with TDT.

Key words: Thalassemia, parathyroid hormone, calcium, phosphate. 
Introduction

$\mathbf{T}$

halassemia is a heterogeneous group of inherited recessive genetic disorder of hemoglobin synthesis ${ }^{1-3}$. It is

characterized by complete absence or reduced synthesis of alpha or beta globin chains leading to ineffective erythropoiesis and anemia. It is an autosomal disorder in which point mutation or deletion occur in the alpha or beta globin gene on chromosome 16(alpha) and 11(beta) ${ }^{4-6}$. A World Health Organization (WHO) data shows that about $3 \%$ population are carrier of beta thalassemia and about $4 \%$ population are carrier of $\mathrm{Hb}-\mathrm{E}$ in Bangladesh. Yearly approximately 6000 children are born with thalassemia in Bangladesh ${ }^{5,7}$.

TDT patients require regular blood transfusion to maintain hemoglobin level $>10 \mathrm{gm} / \mathrm{dl}$. But repeated blood transfusion leads to accumulation of excess iron and citrate toxicity in the body ${ }^{8,9}$. Excess iron leads to increase saturation of circulating transferrin, resulting in the emergence of nontransferrin bound iron (NTBI). NTBI produces various reactive oxygen species (ROS) ${ }^{10}$. Enzymatic and non-enzymatic antioxidant systems are protective systems which scavenge these ROS. When production of ROS exceeds the capacity of protective systems, oxidative stress occurs. This oxidative stress causes tissue damage of various system ${ }^{3,11-13}$.

Endocrine dysfunction is a common complication in TDT due to iron overload and inadequate chelation therapy. Hypoparathyroidism is an irreversible condition associated with hypocalcaemia and hyperphosphatemia in patients with TDT. Some investigators reported that, plasma iPTH and serum calcium level significantly reduced and serum phosphate level significantly increased in $\mathrm{TDT}^{10,14-18}$. All these parameters were studied in both gender in others studies. But gender variation of these parameters are important in TDT patients. Therefore, this study has been designed to assess these parameters in male TDT patients.

Methods

This cross sectional study was carried out in the Department of Physiology, BSMMU, Dhaka from March 2018 to February 2019. The protocol of this study was approved by Institutional Review Board (IRB), BSMMU. For this study, 35 TDT male patients of 18 to 40 year were enrolled from the OPD of Hematology and Transfusion Medicine of BSMMU. For comparison, 35 age matched apparently healthy male subjects were selected from the colleagues, relatives, attendance of the patients, hospital stuffs, nursing students and through personal contacts. Consecutive sampling technique was used for sample collection. All the patients were on regular blood transfusion at least for about 5 years. Patients with thyroidectomy, malignancy, acute illness, with nutritional supplement like multivitamins, calcium and vitamin D (within 120 days), malabsorption syndrome, renal insufficiency, taking any drug which affect calcium level were excluded from this study. After selection of the subjects, a detail family, medical and socioeconomic history were recorded, thorough physical examination was done and documented. Anthropometric measurements including height and weight of the subjects were recorded and BMI was calculated. Six ml of fasting venous blood was collected for analysis of hemoglobin, serum albumin, serum alkaline phosphatase, serum creatinine, plasma iPTH, serum total calcium and serum inorganic phosphate levels. Estimation of all these parameters were done by automated analyzer by colorimetric method. The total calcium level was corrected for albumin ${ }^{19}$. For statistical analysis Independent sample $t$ test was done.

\section{Results}

In this study, there was no significant difference in age and serum albumin level in both groups. BMI and hemoglobin level were significantly ( $p$ $<0.001)$ lower and serum ALP level was significantly $(\mathrm{p}<0.001)$ higher in TDT compared to control (Table I). In addition, plasma iPTH and serum corrected calcium level were significantly $(\mathrm{p}<0.001)$ lower and inorganic phosphate level was significantly $(p<0.001)$ higher in TDT than that of control (Table II). Again 1(2.86\%) TDT patients had low iPTH; whereas no control had low iPTH (Table III) ${ }^{30,21}$. 
Table I: Age, BMI, hemoglobin, serum albumin and serum ALP levels in both groups ( $\mathrm{N}=70$ )

\begin{tabular}{lcc}
\hline Parameters & Control $(\mathrm{n}=35)$ & TDT $(\mathrm{n}=35)$ \\
\hline Age $($ Year $)$ & $27.31 \pm 1.11$ & $26.23 \pm 1.23$ \\
BMI $\left(\mathrm{kg} / \mathrm{m}^{2}\right)$ & $22.1 \pm 0.48$ & $17.14 \pm 0.33^{* * *}$ \\
Hemoglobin(gm/dl) & $14.53 \pm 0.17$ & $6.91 \pm 0.31^{* * *}$ \\
Serum albumin(gm/dl) & $4.46 \pm 0.05$ & $4.33 \pm 0.09$ \\
SerumALP(U/L) & $69.03 \pm 2.10$ & $103.31 \pm 8.86^{* * *}$ \\
\hline
\end{tabular}

Data are expressed as mean \pm SE. Statistical analysis was done by independent sample $t$ test. TDT-Transfusion dependent thalassemia, BMI- Body mass index, ALP-Alkaline phosphatase, *** $\mathrm{p} \leq 0.001$.

Table II: Plasma iPTH, serum corrected calcium and inorganic phosphate levels in both groups ( $\mathrm{N}=70)$

\begin{tabular}{lcc}
\hline Parameters & Control $(\mathrm{n}=35)$ & TDT $(\mathrm{n}=35)$ \\
\hline iPTH $(\mathrm{pg} / \mathrm{ml})$ & $39.07 \pm 1.10$ & $32.00 \pm 1.26^{* * *}$ \\
Corrected calcium $(\mathrm{mg} / \mathrm{dl})$ & $9.26 \pm 0.06$ & $8.91 \pm 0.06^{* * *}$ \\
Inorganic phosphate $(\mathrm{mg} / \mathrm{dl})$ & $3.45 \pm 0.10$ & $4.18 \pm 0.15^{* * *}$ \\
\hline
\end{tabular}

Data are expressed as mean \pm SE. Statistical analysis was done by independent sample $t$ test. TDT-Transfusion dependent thalassemia, iPTH- Intact parathyroid hormone. ${ }^{* * *} \mathrm{p}<0.001$.

Table III: Frequency distribution of low iPTH in both groups $(\mathrm{N}=70)$

\begin{tabular}{lcc}
\hline iPTH $(\mathrm{pg} / \mathrm{ml})$ & Control $(\mathrm{n}=35)$ & TDT $(\mathrm{n}=35)$ \\
& No. $(\%)$ & No. $(\%)$ \\
\hline Low $(<15)$ & $00(0)$ & $1(2.86)$ \\
Normal $(15-65)$ & $35(100)$ & $34(97.14)$ \\
\hline
\end{tabular}

Data are expressed as no. \%. TDT- Transfusion dependent thalassemia. iPTH- Intact parathyroid hormone.

\section{Discussion}

The present study was done to observe the parathyroid function in adult male patients with TDT. In our study, plasma iPTH and serum total calcium levels were significantly lower in TDT patients than that of healthy control. Again, serum inorganic phosphate and ALP levels were significantly higher in TDT patients than that of healthy control. Similar results were reported by other researchers ${ }^{10,14-18}$. But they found these results in both male and female TDT patients. The present result did not indicate any different trend in these parameters. In this study plasma
iPTH was significantly lower in TDT patients and $2.86 \%$ patients had low iPTH. The results of this study suggest that parathyroid function was reduced in TDT patients.

The cause of parathyroid dysfunction in TDT patients is not clear. But literatures suggest that deposition of iron due to repeated blood transfusion in the parathyroid glands is attributed to TDT. In TDT patients iron overload is caused by repeated blood transfusion. This excess iron leads to increase saturation of transferrin. With increasing severity of iron overload, the iron binding capacity of circulating transferrin is 
exceeded, resulting in the emergence of nontransferrin bound iron (NTBI). NTBI produces ROS; such as superoxide anion $\left(\mathrm{O}_{2}^{-}\right)$, hydroxyl radical $(\mathrm{OH} \cdot)$, singlet oxygen and hydrogen peroxide $\left(\mathrm{H}_{2} \mathrm{O}_{2}\right)$ which cause oxidative stress $^{13}$. The ROS causes peroxidation of membrane lipids yielding peroxides, which are themselves unstable and reactive; propagating an autocatalytic chain reactions. These reactions ultimately result in mitochondrial, lysosomal and sarcolemmal membrane damage $e^{3,20,21}$. So, it can be stated that iron overload causes parathyroid glandular damage by oxidative stress. Possibly some other factors with iron overload is associated with developing parathyroid dysfunction. This can be described as individual sensitivity to iron toxicity, the ability of the cell to protect itself against inorganic iron, a number of surface transferrin receptors in the cell. Genetic risk factors like thalassemia genotype $\left(\hat{a}^{0} / \hat{a}^{0}\right)$ and hematological phenotype of the disease can also play an essential role in the development of parathyroid dysfunction ${ }^{18,24}$. However this is only assumption and further studies are needed to explore the exact mechanism of developing parathyroid dysfunction.

\section{Conclusion}

From the results of this study, it is concluded that, parathyroid hormone secretion significantly reduced in TDT. So, to prevent this complications an effective chelation therapy should be started as early as possible to avoid iron overload induced organ failure. Well balanced nutrition, patient education, diet counseling and supplementation with calcium and vitamin $\mathrm{D}$ for TDT patients can be highly recommended. Regular monitoring of plasma iPTH, serum calcium, inorganic phosphate and serum ALP should also be done, so that early management can be taken to prevent complication.

\section{Conflict of interest: None.}

Acknowledgement

The authors acknowledge the Department of Hematology and Transfusion Medicine, BSMMU, Dhaka for their kind co-operation during sample collection and Armed Forces Institute of Pathology, Dhaka cantonment regarding laboratory tests.

\section{References}

1. aMuncie HL, Campbell JS. Alpha and beta thalassemia. Am Fam Physician 2009;80(4):33944.

2. Marengo-Rowe AJ. The thalassemia and related disorders. Proc (Bay Univ Med Cent) 2007;20(1): 27-32.

3. Gupta KK, Mishra A, Tiwari A. Production of reactive oxygen species, its effect, drugs and plant extract used as an antioxidant, chelator on thalassemic patients: a review. Int J Pharm Sci Res2011;2(9):2278-85.

4. Rachmilewitz EA, Giardina PJ. How I treat thalassemia. Blood 2011;118(13):3479-88.

5. Amin SK. Prevention of thalassemia by genetic counseling. Anawer khan Mod. Med. Coll.J.2011; 2(2):26-28.

6. Saboor M, Qudsia F, Qamar K, Moinuddin M. Levels of calcium, corrected calcium, alkaline phosphatase and inorganic phosphatase in patients' serum with â-thalassemia major on subcutaneous deferoxamine. J Hematol Thromb Dis2014;2(2):1-2.

7. Tahura S, Selimuzzaman MD, Khan W. Thalassemia prevention: Bangladesh perspective - A current update. Bangladesh J Child Health 2016;40(1):3138 .

8. Goyal M, Abrol P, Lal H. Parathyroid and calcium status in patients with thalassemia. Ind J Clin Biochem2010;25(4):385-87.

9. Sleem GAAM, Al-Zakwani IS, Almuslahi M. Hypoparathyroidism in Adult Patients with BetaThalassemia Major. Sultan Qaboos Univ Med J 2007;7(3):215-18.

10. Hershko C. Pathogenesis and management of iron toxicity in thalassemia. Ann NY Acad Sci 2010;1202(1):1-9.

11. Hagag AA, El-Shanshory MR, Abo El-Enien AM. Parathyroid function in children with beta thalassemia and correlation with iron load. Adv Pediatr Res 2015;2(3):1-6.

12. Viprakasit V, Origa R. Genetic basis, pathophysiology and diagnosis. In: Cappellini MD, Cohen A, Porter J, Taher A, Viprakasit V, editors. Guidlines for the 
management of transfusion dependent thalassemia (TDT). Nicosia: Cyprus; 2014.p.14-26.

13. Porter J, Viprakasit V. Iron overload and chelation. In: Cappellini MD, Cohen A, Porter J, Taher A, Viprakasit $\mathrm{V}$, editors. Guideline for the management of transfusion dependent thalassemia (TDT). Nicosia: Cyprus; 2014.p.42-97.

14. Galanello R, Origa R. Beta thalassemia. Orphanet J Rare Dis 2010;5(11):1-15.

15. Basha NHP, Shetty B, Shenoy UV. Prevalence of hypoparathyroidism (HPT) In Beta Thalassemia Major. J Clin Diagn Res 2014;8(2):24-26.

16. Modi AS, Poornima RT, Murthy DSJ. Serum calcium and phosphate levels in patients with â-thalassemia major. Int J Pharma Bio Sci 2012;2(4):156-70.

17. Angelopoulus NG, Goula A, Rombopoulus G, Kaltzidou V, Katounda E, Kaltsas D, Tolis G. Hypoparathyroidism in transfusion- dependent patients with â-thalassemia. J Bone Miner Metab 2006;24:138-45.
18. Aleem A, Al-Momen A, Al-Harakati MS, Hasan A and Al-Fawaz I. Hypocalcemia due to hypoparathyroidism in â-thalassemia major patients. Ann Saudi Med 2000;20(5-6):364-66.

19. Risteli J, Winter WE, Kleerekoper M, Risteli L. 2012. Bone and Mineral Metabolism. In: Burtis CA, Ashwood ER, Bruns DE, editors. Tietz Textbook of Clinical Chemistry and Molecular Diagnostics. 5th ed. USA: Elsevier; p. 1733-1802.

20. Kumar V, Abbas AK and Aster JC, editors. Robbins and Cotran Pathologic Basis of Disease. $9^{\text {th }}$ ed. India (New Delhi): Elsevier 2015;p.31-68.

21. Das TK, Wati MR, Wati MR, Fatima-Shad K. Oxidative Stress Gated by Fenton and Haber Weiss Reactions and Its Association with Alzheimer's Disease. Arch Neurosci 2014;2(3): e20078.

22. Hamidieh AA, Moradbeag B, Pasha F, Jalili M, Hadjibabaie M, Keshavarznia M. High prevalence of hypoparathyroidism in patients with betathalassemia major. Int $\mathrm{J}$ Hematol Oncol Stem Cell Res 2009;3(3):17-20. 